\title{
Membrane Traffic Within the Golgi Apparatus
}

\author{
Benjamin S. Glick ${ }^{1,4}$ and Akihiko Nakano ${ }^{2,3}$ \\ ${ }^{1}$ The University of Chicago, Department of Molecular Genetics and Cell Biology, 920 East 58th \\ Street, Chicago, IL 60637, USA, Tel. 773-702-5315, bsglick@uchicago.edu \\ ${ }^{2}$ Molecular Membrane Biology Laboratory, RIKEN Advanced Science Institute, Wako, Saitama \\ 351-0198, Japan, nakano@riken.jp \\ ${ }^{3}$ Department of Biological Sciences, Graduate School of Science, The University of Tokyo, 7-3-1 \\ Hongo, Bunkyo-ku, Tokyo 113-0033, Japan, nakano@biol.s.u-tokyo.ac.jp
}

\section{Abstract}

Newly synthesized secretory cargo molecules pass through the Golgi apparatus while resident Golgi proteins remain in the organelle. However, the pathways of membrane traffic within the Golgi are still uncertain. Most of the available data can be accommodated by the cisternal maturation model, which postulates that Golgi cisternae form de novo, carry the secretory cargoes forward, and ultimately disappear. The entry face of the Golgi receives material that has been exported from transitional ER sites, and the exit face of the Golgi is intimately connected with endocytic compartments. These conserved features are enhanced by cell type-specific elaborations such as tubular connections between mammalian Golgi cisternae. Key questions remain about how Golgi cisternae form and then mature, how resident Golgi proteins recycle, how Golgi compartments achieve their identities, how the unique architecture of the Golgi is established, and how different structural elements contribute to Golgi function.

\section{Keywords}

cisternal maturation; COPI; transitional ER; recycling endosomes; Golgi matrix; Golgi tubules

\section{INTRODUCTION}

The structure of an organelle mirrors its function. A striking example is the Golgi apparatus (Mollenhauer \& Morré 1991). In most eukaryotes, the Golgi consists of one or more stacks of disk-shaped cisternae. This organelle receives secretory cargoes that have been exported from the ER at specialized transitional ER (tER) sites, and it serves as a "carbohydrate factory" to process oligosaccharide side chains on newly synthesized glycoproteins and glycolipids (Mellman \& Simons 1992). At the exit face of the Golgi, secretory cargoes are sorted into a variety of transport carriers for delivery to their final destinations.

These conserved functions are reflected in a conserved biochemical polarity of the Golgi (Dunphy \& Rothman 1985, Farquhar 1985). Cisternae at the cis face of the Golgi contain resident enzymes that act at early steps of secretory cargo processing. Adjacent cisternae in the medial portion of the stack contain enzymes that act at intermediate steps, while cisternae near the trans face of the Golgi contain enzymes that act at late steps. COPI-coated transport vesicles bud from all of these cisternae and appear to play a central role in Golgi function

\footnotetext{
${ }^{4}$ Corresponding author .
} 
(Ladinsky et al 1999, Rothman \& Wieland 1996). Beyond the trans cisternae is the trans-Golgi network (TGN), a reticular compartment that produces clathrin-coated vesicles and secretory carriers (Bard \& Malhotra 2006, De Matteis \& Luini 2008).

Other features of the Golgi are less conserved. For example, mammalian cells contain a ribbon of laterally interconnected Golgi stacks near the centrosome (Rambourg \& Clermont 1990).

At the other end of the spectrum is the budding yeast Saccharomyces cerevisiae, in which the Golgi consists of individual cisternae scattered throughout the cytoplasm (Preuss et al 1992). Despite these differences, the molecular mechanisms of Golgi function seem to be similar in mammals and yeast (Duden \& Schekman 1997).

The major unresolved question in this field is how secretory cargoes traverse the Golgi. A related question is how resident Golgi proteins localize to different compartments of the organelle. Cargo transport and Golgi compartmental identity are the focus of this review. Part of the ongoing debate revolves around uncertainties about the detailed structure of the Golgi and about the roles of specific structural features. We suggest that these issues can be addressed by combining information from multiple experimental organisms, thereby highlighting universal principles. Attempts have been made to propose comprehensive models for Golgi function, and in the end, concepts from several models will likely contribute to an integrated picture.

\section{MODELS FOR INTRA-GOLGI CARGO TRANSPORT}

For many years, the prevailing idea was that Golgi cisternae are stable compartments (Figure 1a). In this scenario, resident Golgi proteins are retained in the cisternae while secretory cargoes are transported from one cisterna to the next in anterograde COPI vesicles (Rothman \& Wieland 1996). The retention mechanism for resident Golgi proteins was thought to be exclusion from anterograde vesicles (Colley 1997). This model has several advantages. It explains the polarity of the stack by viewing the Golgi as a series of distinct sub-organelles, each of which has a characteristic set of resident proteins (Dunphy \& Rothman 1985, Farquhar 1985). It also accounts for the observation that COPI transport vesicles are abundant around the Golgi, apparently forming and fusing at the cisternal rims (Farquhar 1985, Orci et al 1986).

Biochemical evidence for the stable compartments model came from a cell-free reconstitution system, which implicated COPI vesicles and the vesicle fusion machinery in intra-Golgi transport (Rothman \& Wieland 1996).

However, the stable compartments model has encountered difficulties. The Golgi stacks in many organisms transport cargoes that are too large to fit in conventional COPI vesicles. Examples include scales in algae (Becker \& Melkonian 1996) and procollagen in mammalian fibroblasts (Bonfanti et al 1998). Large cargoes could potentially move through the mammalian Golgi in "megavesicles" (Volchuk et al 2000), but procollagen appears to remain within the Golgi cisternae (Mironov et al 2001), and no putative megavesicles have been seen in algae (Donohoe et al 2007). Moreover, strong evidence has been obtained for retrograde COPIdependent transport, but the evidence for anterograde COPI-dependent transport is less solid (Rabouille \& Klumperman 2005).

These problems were addressed by the cisternal maturation model (Glick \& Malhotra 1998, Pelham 1998), which is an updated version of the cisternal progression model that had long been advocated by morphologists (Mollenhauer \& Morré 1991). The idea is that cisternae assemble at the cis face of the stack, then progress through the stack while carrying the secretory cargoes forward, then ultimately disintegrate at the TGN stage by forming transport carriers (Figure 1b). Resident Golgi proteins are postulated to recycle from older to younger cisternae, thereby driving cisternal maturation. Transmembrane Golgi proteins might recycle in retrograde COPI vesicles that become tethered to their target cisternae by the COG complex 
(Smith \& Lupashin 2008, Ungar et al 2006). Peripheral Golgi proteins might recycle by dissociating from a given cisterna and then binding to a younger cisterna.

The cisternal maturation model is appealing for many reasons. It fits with abundant morphological data suggesting that cisternae form at the cis face of the stack and peel off at the trans face (Mollenhauer \& Morré 1991). If cisternae are indeed the anterograde carriers, the mechanism for transporting large cargoes is clear (Becker \& Melkonian 1996). The cisternal maturation model includes roles for COPI vesicles and the membrane fusion machinery, which are presumed to mediate the retrograde transport of resident Golgi proteins (Glick \& Malhotra 1998, Love et al 1998). This model can explain why a given resident Golgi protein may be present in multiple Golgi compartments (Rabouille et al 1995), and why resident Golgi proteins move rapidly both within and between cisternae (Cole et al 1996b, Harris \& Waters 1996, Hoe et al 1995, Opat et al 2001). Finally, the cisternal maturation model makes testable predictions.

One prediction is that different secretory cargoes should traverse the stack at the same rate. Indeed, the bulky soluble protein procollagen was observed to move through the Golgi stack at the same rate as the smaller transmembrane glycoprotein VSV-G (Mironov et al 2001), and two glycoproteins in S. cerevisiae were found to transit through the Golgi at similar rates (Losev et al 2006). Another prediction is that if an individual cisterna matures from cis to trans, its complement of resident Golgi proteins should change over time. This change in resident protein composition was visualized by live-cell fluorescence microscopy of Golgi cisternae in S. cerevisiae (Losev et al 2006, Matsuura-Tokita et al 2006). The rate of cisternal maturation was similar to the rate of secretory cargo transport through the Golgi (Losev et al 2006), suggesting that cisternal maturation is the primary means of anterograde intra-Golgi transport in yeast. Yet another prediction is that cisternal maturation should require COPI. The data in this regard are not yet definitive, but in a yeast strain containing a defective COPI protein, cisternal maturation was slowed (Matsuura-Tokita et al 2006).

Despite the explanatory power of cisternal maturation, questions remain about a key issue: the content of COPI vesicles. The cisternal maturation model predicts that COPI vesicles should be enriched in resident Golgi proteins but depleted in secretory cargoes, while the stable compartments model makes the opposite prediction (Glick et al 1997, Rabouille \& Klumperman 2005). There seems to be a consensus that mammalian COPI vesicles contain some resident Golgi proteins, including the SNARE proteins that mediate membrane fusion and the KDEL receptor that captures escaped ER residents for retrieval to the ER (Cosson et al 2005, Martínez-Menárguez et al 2001, Orci et al 1997). However, the data regarding resident Golgi glycosylation enzymes are conflicting. Several groups have reported that glycosylation enzymes are concentrated in COPI vesicles (Gilchrist et al 2006, Love et al 1998, MartínezMenárguez et al 2001), and yeast Vps74 was recently identified as a putative COPI adaptor for recruiting glycosylation enzymes (Schmitz et al 2008, Tu et al 2008), but other groups have reported that glycosylation enzymes are depleted in COPI vesicles relative to Golgi cisternae (Cosson et al 2002, Kweon et al 2004, Orci et al 2000a). A similar debate focuses on small secretory cargoes. Some researchers have reported that COPI vesicles contain proinsulin and VSV-G (Orci et al 1997), but others have reported that small secretory cargoes such as VSVG and albumin are depleted in COPI vesicles (Dahan et al 1994, Gilchrist et al 2006, MartínezMenárguez et al 2001). New methods may be needed to resolve these controversies. A promising approach is correlative photooxidation, which allows the location of GFP-tagged proteins to be visualized by electron microscopy (Grabenbauer et al 2005).

The disparate observations about COPI-dependent transport could be reconciled by assuming that cells produce two classes of COPI vesicles: a class that mediates anterograde transport of secretory cargoes, and a second class that mediates retrograde transport of resident Golgi proteins (Pelham \& Rothman 2000). Evidence for this idea has come from immunoelectron 
microscopy of mammalian cells (Orci et al 2000b, Orci et al 1997) and from the biochemical isolation of two mammalian COPI vesicle populations that contain distinct vesicle tethers (Malsam et al 2005). However, an alternative possibility is that both classes of COPI vesicles travel in the retrograde direction, with one class mediating intra-Golgi recycling while the second class mediates recycling from the cis-Golgi to the ER. This latter interpretation was favored in a morphological study that identified two classes of COPI vesicles in plant and algal cells (Donohoe et al 2007). Thus, the directionality of COPI-dependent traffic remains an open question.

Are COPI vesicles the only game in town when it comes to transport between Golgi cisternae? A potential alternative is tubular connections between different cisternae within the same stack. This idea has been discussed for many years (Weidman 1995). In tomographic reconstructions of mammalian Golgi stacks, continuities between heterologous cisternae were rare but could occasionally be seen when the cells were stimulated to secrete at high levels (Marsh et al 2004). However, other researchers have presented morphological evidence that during active secretion, a typical mammalian Golgi stack contains multiple tubular connections between heterologous cisternae (Trucco et al 2004). The quantitative discrepancies between these studies have yet to be resolved. Also uncertain are the functional consequences of intercisternal continuities. One possibility is that some small secretory cargoes enter a "fast lane" and diffuse rapidly through the stack (Figure 2a). If a rapidly diffusing cargo accumulated in the TGN by a concentrative process, the cell could efficiently transport this cargo through the Golgi without moving large amounts of membrane through the stack by cisternal progression. A complementary possibility is that resident Golgi transmembrane proteins recycle by diffusing through intercisternal continuities, followed by capture in the appropriate compartment (Figure $2 b$ ). Either or both of these mechanisms could operate in conjunction with COPI vesicle-driven cisternal maturation.

A recent fluorescence microscopy study challenged the basic premise of cisternal maturation and proposed a radically different model (Patterson et al 2008). The major finding was that for various secretory cargoes, the molecules within the Golgi region exited in an exponential manner. By constrast, the cisternal maturation model implies that secretory cargo molecules within the Golgi should progress through the stack as if on a conveyor belt, and should therefore exit to the cell surface in a linear manner. One technical consideration is that the Golgi region as visualized by fluorescence microscopy also contains other compartments such as tER sites and recycling endosomes, so the observed exit kinetics may not exclusively reflect transport from the Golgi to the plasma membrane. In any case, the data were interpreted as evidence for a rapid partitioning mechanism in which the Golgi consists of a single intermixed compartment that contains processing and export domains (Patterson et al 2008). It will be important to test this new concept and to explain the exponential kinetics of secretory cargo exit from the Golgi region.

\section{THE TRANSITIONAL ER-GOLGI RELATIONSHIP}

Transport through the secretory pathway begins with cargo export at tER sites, also known as ER exit sites. tER sites produce COPII-coated vesicles that carry the secretory cargoes. COPII vesicle biogenesis has been reviewed extensively elsewhere (Hughes \& Stephens 2008, Sato $\&$ Nakano 2007). Here, we will focus on the functional relationship between tER sites and the Golgi.

In many eukaryotic cells, Golgi stacks are closely associated with tER sites (Becker \& Melkonian 1996). This relationship can be interpreted in light of the cisternal maturation model, which views the Golgi as a dynamic outgrowth of the tER (Glick \& Malhotra 1998). The premise is that COPII vesicles fuse homotypically to nucleate the formation of new cis-Golgi 
cisternae. Evidence has been obtained for such a process (Bentley et al 2006, Cai et al 2007), but cisternal assembly probably involves more than homotypic fusion. For example, most of the resident Golgi proteins in a new cisterna may come not from the ER, but rather from retrograde COPI vesicles produced by existing Golgi membranes (Glick et al 1997, He et al 2004). Moreover, COPII vesicles may fuse not only with one another, but also with a fully formed cisterna (Staehelin \& Kang 2008). Despite these caveats, tER sites can plausibly be viewed as the birthplace of Golgi cisternae.

This emphasis on the tER-Golgi relationship has been useful for analyzing Golgi biogenesis and inheritance. In the budding yeast Pichia pastoris, a typical cell contains several Golgi stacks, each of which is associated with a tER site (Rossanese et al 1999). Live-cell imaging revealed that Golgi stacks in $P$. pastoris form de novo in conjunction with new tER sites (Bevis et al 2002). Similar results have been seen in the protozoan Trypanosoma brucei (He et al 2004). In some organisms, an ordered fission of tER sites is accompanied by duplication of the associated Golgi stacks (Bracker et al 1996, Rossanese \& Glick 2001). The appearance of new cis-Golgi cisternae in the budding daughter cells of $S$. cerevisiae requires the delivery of ER membranes into the bud (Reinke et al 2004). In certain mammalian cell lines, after the Golgi breaks down during mitosis, the subsequent reassembly of Golgi cisternae occurs next to tER sites (Altan-Bonnet et al 2006). These findings can be understood as variations on the same theme: tER sites nucleate the formation of Golgi structures.

How does a new Golgi stack form? When the mammalian Golgi was thoroughly disrupted with a combination of the drugs brefeldin A (BFA) and H89, removal of the drugs led to reassembly of a functional Golgi, suggesting that a new Golgi stack can arise by self-organization (Puri \& Linstedt 2003). Such a process was modeled in a recent computer simulation (Gong et al 2008). Golgi assembly seems to be an orderly process in which so-called "matrix" proteins are put in place first, thereby establishing a scaffold to localize other resident Golgi proteins (Ho et al 2006, Jiang et al 2006, Puri \& Linstedt 2003). This scaffold can be seen in the vicinity of tER sites when mammalian cells are treated with BFA alone (Seemann et al 2000, Ward et al 2001). Yet even though the Golgi can evidently assemble from scratch, Golgi formation in many cells may normally follow a more efficient pathway that builds on an existing template (Lowe \& Barr 2007).

\section{GOLGI STACKING AND CISTERNAL DOMAINS}

In addition to serving as a possible scaffold for Golgi assembly, matrix proteins have been implicated in Golgi structure. Electron microscopy first identified the Golgi matrix as a dense network that surrounds Golgi stacks and excludes ribosomes (Staehelin \& Moore 1995). Later work identified coiled-coil "golgins" as likely components of the Golgi matrix (Short et al 2005, Shorter \& Warren 2002). It is possible that matrix proteins hold the cisternae together. Indeed, proteolysis experiments showed that cisternae are held together by proteinaceous bridges (Cluett \& Brown 1992, Mollenhauer \& Morré 1991). A cell-free Golgi assembly assay suggested that stacking of the mammalian Golgi involves golgins as well as the peripherally associated GRASP proteins (Shorter \& Warren 2002). However, in vivo studies have led to conflicting interpretations about the stacking roles of GRASPs and golgins (Puthenveedu et al 2006, Wang et al 2008). Both classes of proteins have also been assigned other functions, most notably vesicle tethering (Short et al 2005). The golgins are postulated to act as "tentacles" that capture vesicles and guide them through the matrix (Hayes et al 2009, Sinka et al 2008).

Individual Golgi cisternae are often assumed to be homogeneous compartments, but lateral segregation within the cisternal membranes might be functionally relevant. An obvious membrane specialization is tubules that project from the rims of Golgi cisternae. Golgi tubules have been seen in a variety of organisms (Boulaflous et al 2008, Ladinsky et al 1999, 
Mogelsvang et al 2003, Sciaky et al 1997). In mammalian cells, Golgi tubulation requires lysophospholipids that are generated by cytoplasmic phospholipase A2 enzymes (Brown et al 2003). No cytoplasmic phospholipase A2 has been identified in yeast, suggesting that multiple mechanisms can tubulate Golgi membranes.

Golgi tubulation can be enhanced by treating mammalian cells with BFA, which inhibits the action of the COPI and BARS proteins that normally sever Golgi-derived buds to produce vesicles (Yang et al 2008). BFA-induced tubules eventually fuse with the ER, resulting in disappearance of a distinct Golgi apparatus (Sciaky et al 1997). Fusion often occurs near tER sites (Mardones et al 2006), suggesting that BFA-induced tubules are an exaggerated form of a retrograde Golgi-to-ER carrier. This model is supported by the finding that inhibitors of Golgi tubulation also block retrograde Golgi-to-ER traffic (Brown et al 2003). Another means for enhancing tubulation of the mammalian Golgi is to lower the temperature to $15^{\circ} \mathrm{C}$ (MartínezAlonso et al 2007). These low temperature-induced tubules concentrate a subset of resident Golgi proteins and seem to be functionally distinct from BFA-induced tubules. Perhaps low temperature prolongs the lifetime of tubules that normally fuse to generate connections within the Golgi itself. At physiological temperatures, these tubules might fuse homotypically with equivalent cisternae to form the Golgi ribbon (Marra et al 2007, Puthenveedu et al 2006), or might fuse heterotypically with functionally distinct cisternae to generate the intercisternal continuities described above.

Another possible function of Golgi tubules is to generate fenestrations within cisternae. Such fenestrations are a common feature of the Golgi (Ladinsky et al 1999, Rambourg \& Clermont 1990), but their origin is still mysterious. It was previously suggested that fenestrations stem from "periplasmic fusion" events that initiate with the lumenal leaflets of the cisternal membranes (Rothman \& Warren 1994), but no machinery for periplasmic fusion has been identified. An alternative possibility is that fenestrations form when tubules loop around and fuse homotypically with the originating cisterna (Figure 3) (Weidman et al 1993). This mechanism implies that fenestrations are generated at the cisternal rims. Consistent with this model, mammalian Golgi stacks have more fenestrations near the cisternal rims than in the central portions (Rambourg \& Clermont 1990). In P. pastoris Golgi stacks, fenestrations are present near the rims of early cisternae and apparently migrate inward as the cisternae progress through the stack (Mogelsvang et al 2003).

What is the role of fenestrations? They increase the surface-to-volume ratio of the cisternae, and they increase the fraction of the membrane that is highly curved. This additional curved membrane area may increase the capacity of a cisterna for producing COPI vesicles. Moreover, the biophysical properties of curved membranes may lead to protein segregation, thereby generating biochemically distinct domains. For example, morphological data suggested that the rims of cisternae are different from the central regions (Weidman et al 1993), and immunolabeling indicated that SNARE proteins are concentrated at cisternal rims (Cosson et al 2005).

Fluorescence microscopy has provided additional evidence for domain formation within cisternae. In yeast, different fluorescently tagged Golgi proteins sometimes appear to be segregated within the same cisternae (Losev et al 2006, Matsuura-Tokita et al 2006); and in mammalian cells, secretory cargoes are reportedly segregated from resident Golgi proteins within the cisternae (Patterson et al 2008). One caveat is that when the Golgi contains large amounts of a given protein, any self-affinity —either intrinsic or due to a fusion tag — could result in artificial clustering within the membrane. Despite these concerns, the concept of protein partitioning within cisternae deserves further study. Such partitioning might help to sort resident Golgi proteins for retrograde transport during cisternal maturation. 


\section{THE TGN-ENDOSOME RELATIONSHIP}

The main function of the TGN is cargo sorting. This topic has been reviewed elsewhere (Bard $\&$ Malhotra 2006, Luini et al 2008), so we will summarize very briefly. The TGN contains multiple sorting domains. Clathrin cooperates with adaptors to produce vesicles that carry certain cargoes from the TGN to endosomes. Meanwhile, secretory cargoes are delivered from the TGN to the plasma membrane by a variety of routes. Many secretory carriers are not conventional vesicles, but instead are pleiomorphic structures whose formation involves reactions of lipid metabolism (Brossard et al 2007). In polarized cells, apically- and basolaterally-targeted secretory cargoes are segregated into different types of carriers at the TGN. Regulated secretory cargoes condense in the TGN, and are captured in structures that pinch off and condense further to form dense-core secretory granules (Dikeakos \& Reudelhuber 2007). In yeast, carriers generated by a novel "exomer" coat deliver selected secretory cargoes from the TGN to the plasma membrane (Trautwein et al 2006, Wang et al 2006).

The TGN differs from earlier Golgi cisternae in several respects. For example, many TGN proteins have cytosolic tails that contain signals for adaptor-mediated retrieval from endosomes (Bonifacino \& Rojas 2006, Maxfield \& McGraw 2004), whereas the glycosylation enzymes found in earlier Golgi cisternae use a different type of localization signal (Opat et al 2001). Another difference is that the TGN produces clathrin-coated vesicles but not COPI vesicles, whereas earlier Golgi cisternae produce COPI vesicles but not clathrin-coated vesicles (Donohoe et al 2007, Ladinsky et al 2002). The distinction between the TGN and the rest of the Golgi is particularly evident in plant cells, where the TGN is often physically separate from the Golgi stack (Foresti \& Denecke 2008, Staehelin \& Kang 2008, Uemura et al 2004).

In addition to serving as the exit face of the Golgi, the TGN is the interface between the Golgi and the endocytic system. Many proteins are found in both endosomes and the TGN (Bonifacino \& Rojas 2006, Johannes \& Popoff 2008). As a result, the boundary between these two compartments is sometimes blurry. This point can be illustrated by four examples. (1) When mammalian cells are treated with BFA to fuse Golgi cisternae with the ER, the TGN fuses instead with endosomes (Lippincott-Schwartz et al 1991, Wood et al 1991). (2) Yeast Sec7 is a guanine nucleotide exchange factor that is often used as a marker for the trans-Golgi and TGN (Franzusoff et al 1991, Mogelsvang et al 2003, Reinke et al 2004), yet a fluorescent dye can be endocytosed to a Sec7-containing compartment (Lewis et al 2000). Moreover, the mammalian Sec7 homologues are present on both the TGN and endosomes (Shen et al 2006, Shin et al 2004). (3) Various clathrin adaptors mediate traffic between the TGN and endosomes, but this traffic has been reported to be either TGN-to-endosome or endosome-to-TGN or both (Copic et al 2007, Hinners \& Tooze 2003, Liu et al 2008). (4) During endocytosis into plant cells, the internalized material moves rapidly to the TGN (Foresti \& Denecke 2008, Robinson et al 2008).

The TGN-endosome link is especially clear for recycling endosomes, which return endocytosed components to the plasma membrane (Maxfield \& McGraw 2004). Mammalian recycling endosomes are often found near the Golgi. Strikingly, a subset of mammalian secretory proteins pass through recycling endosomes en route to the cell surface (Ang et al 2004, Manderson et al 2007). A similar pathway exists in S. cerevisiae, where a subset of the secretory proteins reach the cell surface via endosomes (Harsay \& Schekman 2002). In plant cells, the TGN and recycling endosomes have similar properties, and might sometimes be domains of a single continuous organelle (Foresti \& Denecke 2008, Robinson et al 2008).

These results can be integrated by viewing the recycling endosome as an "optional" stage in the Golgi maturation pathway (Rodriguez-Boulan \& Müsch 2005). As diagrammed in Figure 4 , we suggest that portions of a maturing TGN cisterna fuse with recycling endosomes. Some 
secretory cargoes depart from the TGN to the cell surface before this fusion event, but other secretory cargoes reach the cell surface in carriers produced by recycling endosomes. Thus, both the TGN and recycling endosomes sort proteins destined for either the endosomal/ lysosomal system or the plasma membrane, and these overlapping functions are reflected in a partially shared sorting machinery.

\section{VARIABLE FEATURES OF THE GOLGI}

To understand the core properties of the Golgi, we must distinguish between conserved and cell type-specific features. A case in point is the close association of mammalian trans-Golgi cisternae with specialized ER membranes that have been designated "trans ER" (Mogelsvang et al 2004). This association facilitates ceramide transfer between the ER and Golgi (Hanada et al 2007, Peretti et al 2008). However, nothing resembling the trans ER has been observed in other eukaryotes.

Another unique feature of the mammalian Golgi is its interaction with microtubules. In a typical mammalian cell, minus end-directed transport along microtubules concentrates the Golgi near the centrosome, where the cisternae fuse laterally to generate a ribbon of interconnected stacks (Figure 5a) (Kreis et al 1997, Rambourg \& Clermont 1990). This membrane fusion might be mediated by tubules that fuse homotypically not with the originating cisternae, as depicted in Figure 3, but rather with adjacent cisternae (Marra et al 2007, Puthenveedu et al 2006). The Golgi ribbon often consists of several unconnected pieces, but the mammalian Golgi is essentially a unitary organelle in which resident proteins diffuse rapidly between stacks (Cole et al 1996b).

What is the reason for the unusual structure and location of the mammalian Golgi? One benefit is that glycosylation appears to be more efficient in an interconnected Golgi ribbon (Puthenveedu et al 2006). However, the main benefit probably involves post-Golgi transport to the plasma membrane. Whereas most eukaryotes use actin cables for the transport of secretory carriers, mammalian cells use microtubules for the polarized delivery of secretory carriers to domains of the plasma membrane (Kreis et al 1997). Thus, secretory cargoes first move inward along microtubules to the cis-Golgi, then outward along microtubules from the TGN to the plasma membrane. Because all of the Golgi stacks are near the centrosome, TGNderived secretory carriers engage efficiently with microtubules. This process is enhanced by additional microtubules that are nucleated directly at the TGN (Efimov et al 2007).

As a result of microtubule-dependent transport, the centralized mammalian Golgi is distant from peripheral tER sites. However, when microtubules are disrupted with nocodazole, the Golgi ribbon is replaced by individual Golgi stacks located next to tER sites (Cole et al 1996a, Hammond \& Glick 2000). The Golgi stacks in nocodazole-treated cells are functional, but as would be expected, secretion becomes nonpolarized (Rogalski et al 1984). These findings indicate that the Golgi ribbon is an elaboration on the basic theme of the tER-Golgi unit.

The existence of a microtubule-dependent Golgi ribbon has additional consequences that are specific to mammalian cells. During mammalian mitosis, the Golgi ribbon breaks down, probably to ensure that Golgi material is partitioned equally between the daughter cells (Shorter \& Warren 2002). By contrast, plant and fungal Golgi stacks remain intact during mitosis (Rossanese \& Glick 2001). Also unique to mammalian cells is a vesicular-tubular ER-Golgi intermediate compartment (ERGIC) (Appenzeller-Herzog \& Hauri 2006). ERGIC clusters form near peripheral tER sites and then travel inward along microtubules to deliver secretory cargoes to the Golgi ribbon (Kreis et al 1997, Presley et al 1997). ERGIC clusters apparently dock at the cis face of the Golgi, where they fuse homotypically to generate new cisternae (Ladinsky et al 1999). Unexpectedly, the ERGIC as a whole is a long-lived compartment that 
includes stationary elements located next to tER sites (Appenzeller-Herzog \& Hauri 2006, Ben-Tekaya et al 2005). It is unclear whether other cell types contain a compartment analogous to the stable mammalian ERGIC.

The plant Golgi also interacts with the cytoskeleton, but in this case entire Golgi stacks move along actin cables (Figure 5b) (Boevink et al 1998, Nebenführ et al 1999). Golgi stacks remain in the vicinity of ER membranes that are linked to the actin network. Fluorescence microscopy has indicated that plant COPII proteins are concentrated next to Golgi stacks (Hanton et al 2008, Yang et al 2005), and electron tomography has revealed COPII vesicles budding from the plant ER (Kang \& Staehelin 2008). There is an ongoing debate about whether plant Golgi stacks move in conjunction with associated tER sites, or whether the stacks collect COPII vesicles from stationary tER sites (Hawes et al 2008, Staehelin \& Kang 2008).

Although the stacked structure of the Golgi is widely conserved, the number of cisternae per stack varies from 3-4 in P. pastoris to about 20 in some algae (Domozych 1991, Mogelsvang et al 2003). The size of the stack seems to be nearly constant in a given cell type. For example, cultured normal rat kidney (NRK) cells typically have 7 cisternae per stack (Ladinsky et al 2002). Why does the size of the Golgi stack differ between cell types? One possible explanation takes into account the role of the Golgi as a carbohydrate factory. When complex structures are being synthesized, the cargoes need to spend longer in the factory, so the stack needs to contain more cisternae (Glick \& Malhotra 1998). There does seem to be a correlation between the number of cisternae per stack and the complexity of the cargoes being synthesized (Becker \& Melkonian 1996), but a rigorous test of this hypothesis will be challenging. An important step will be to determine the molecular mechanism that specifies the number of cisternae per stack.

In some cell types, Golgi cisternae are not arranged in stacks. The lack of cisternal stacking in S. cerevisiae may be partly due to an unusually fragmented tER (Rossanese et al 1999).

Nevertheless, Golgi cisternae in S. cerevisiae can be classified as cis, medial, trans, or TGN based on their resident proteins (Brigance et al 2000, Duden \& Schekman 1997), suggesting that Golgi function in S. cerevisiae resembles that in organisms with a stacked Golgi. This assertion is supported by two additional lines of evidence. First, molecular analysis has revealed extensive conservation between the yeast and mammalian secretory machineries (Duden \& Schekman 1997). Second, S. cerevisiae is closely related to P. pastoris, which contains a stacked Golgi, and these two budding yeasts probably use similar mechanisms throughout the secretory pathway. If this reasoning is valid, then cisternal stacking is dispensable for the basic operation of the Golgi.

Why then has Golgi stacking been largely preserved during evolution (Dacks et al 2003)? Perhaps stacking is a side effect of the high density of tethering proteins associated with Golgi cisternae. This idea can explain why the Golgi matrix includes proteins whose primary function is vesicle tethering (Short et al 2005). The evolution of a nonstacked Golgi might not entail a loss of function, but instead might require specifically overriding the stacking tendency of Golgi cisternae.

\section{SYNTHESIS AND OPEN QUESTIONS}

At present, the cisternal maturation model seems to provide the best fit to the data. We propose that the major, conserved mechanism for transporting secretory cargoes through the Golgi is the progression and maturation of transient cisternae. Some cell types probably use variations on this basic theme. For example, mammalian cells may use tubular connections to facilitate protein transport between heterologous cisternae, and may also interpose a stable ERGIC compartment between the tER and the Golgi. 
Even if a consensus develops around the cisternal maturation concept, many mysteries remain. Below we pose some questions and suggest topics that are ripe for further exploration.

- What processes define cisternal morphology?

It is unclear how Golgi cisternae maintain their flattened shape. The unstacked cisternae in $S$. cerevisiae are often flat (Preuss et al 1992), as are isolated mammalian Golgi cisternae that have been unstacked by protease treatment (Cluett \& Brown 1992), suggesting that stacking is not required to maintain cisternal shape. Golgi cisternae swell when lumenal acidification is blocked (Dinter \& Berger 1998, Maeda et al 2008), presumably because a transmembrane proton gradient is important for controlling cisternal volume. In addition, mechanisms may exist for holding the two faces of a cisterna together. Such a function has been proposed for lumenal Golgi proteins (Cluett \& Brown 1992, Li et al 2007) and also for fenestrations, which may serve as cisternal "spot welds" (Ladinsky et al 1999).

- How does the Golgi matrix assemble and disassemble?

It was postulated that the matrix might serve as a stable template for Golgi formation and inheritance (Seemann et al 2000). This idea now seems unlikely because the matrix is highly dynamic (Miles et al 2001, Puri et al 2004, Ward et al 2001) and because Golgi stacks can apparently form de novo (Bevis et al 2002, Puri \& Linstedt 2003). However, the concept of the matrix as a scaffold is still viable. During the formation of Golgi stacks, matrix components tend to appear before other Golgi proteins, suggesting that the matrix assembles first and lays the foundation for recruiting additional components (Ho et al 2006, Jiang et al 2006, Puri \& Linstedt 2003). It will be interesting to study the assembly pathway of the Golgi matrix.

Disassembly of the Golgi matrix is also important. During cisternal maturation, the stacking interactions between cisternae need to be broken to allow TGN cisternae to escape. Indeed, electron microscopy has suggested that TGN cisternae "peel off" as the Golgi matrix around these cisternae disassembles (Mogelsvang et al 2003, Mollenhauer \& Morré 1991, Rambourg $\&$ Clermont 1990). The mechanisms of matrix disassembly are unknown, but some golgins are regulated by GTPases (Short et al 2005), so an attractive speculation is that GTPase switches are involved.

- What drives cisternal progression?

Golgi cisternae are thought to progress through the stack as they mature, but the driving force for cisternal progression has not been identified. Thermal motion is probably insufficient, especially for stacks with many cisternae (Luby-Phelps 2000). One possibility is that assembly of a new cis cisterna generates a pushing force that moves older cisternae forward. Another possible mechanism involves the Golgi matrix. If a TGN cisterna is pulled away from the stack by cytoskeletal motors, then while this TGN cisterna is still partially embedded in the Golgi matrix, the pulling force should advance the entire set of linked cisternae.

- How is cisternal turnover regulated?

The cell must somehow make new cis-Golgi cisternae at exactly the same rate that it loses TGN cisternae. More generally, membrane traffic into and out of the Golgi must be balanced. Golgi homeostasis is presumably maintained by feedback. For example, the recycling of components from maturing TGN cisternae may be needed for the ongoing maturation of earlier cisternae. Similarly, the recycling of components from the Golgi to the ER may be needed for ongoing ER export.

- How does the Golgi remain polarized?

The polarity of the Golgi stack has long posed a challenge for the cisternal maturation model (Farquhar 1985). To maintain this polarity, resident Golgi proteins of early cisternae must recycle sooner than resident Golgi proteins of later cisternae. One way to achieve differential 
recycling is for the resident Golgi proteins to compete for packaging into retrograde carriers. A simulation predicted that if resident Golgi proteins compete for incorporation into a limited number of retrograde COPI vesicles, the stronger competitors will be concentrated in earlier cisternae (Glick et al 1997). However, this model has not yet been tested experimentally, and other mechanisms for maintaining Golgi polarity have also been proposed (Patterson et al 2008, Weiss \& Nilsson 2000).

\section{- Can COPI vesicles act as long-distance carriers?}

COPI vesicles are dissociative carriers, but their range of movement is unknown. One proposal is that mammalian COPI vesicles are always tethered to nearby cisternae and therefore act exclusively as local carriers (Orci et al 2000b). Yet when mammalian cells were fused, the separate Golgi ribbons readily exchanged material (Rothman et al 1984), presumably by means of COPI vesicles. Moreover, the nonstacked cisternae in S. cerevisiae seem to communicate by vesicular transport (Wooding \& Pelham 1998). A role for COPI vesicles as long-distance carriers can also explain two other observations. First, in T. brucei, a newly formed Golgi stack receives components that are transported through the cytosol from an older Golgi stack (He et al 2004). The relevant carriers have not been identified but are likely to be COPI vesicles. Second, when mammalian cells are treated with nocodazole, Golgi proteins redistribute from the centralized Golgi ribbon to scattered individual Golgi stacks. This redistribution was thought to involve transport through the ER (Cole et al 1996a), but recent data indicate that some resident Golgi proteins redistribute independently of the ER (Pecot \& Malhotra 2006). Again, the most likely carriers are COPI vesicles.

If COPI vesicles do travel long distances, our views of cytoplasmic dynamics may need to be modified. The conventional wisdom is that a vesicle should diffuse through the cytoplasm very slowly (Luby-Phelps 2000). On the other hand, intracellular diffusion seems to be augmented by a constant agitation of the cytoplasm due to molecular motor activity and other processes (Brangwynne et al 2008). A deeper understanding of this topic will have important implications. For example, after photobleaching of mitotic mammalian cells, the rapid recovery of fluorescently tagged transmembrane Golgi proteins was taken as evidence that these proteins must have been diffusing within the ER network (Zaal et al 1999), but other researchers argued that the Golgi proteins were present in vesicles that could move rapidly through the cytoplasm (Axelsson \& Warren 2004).

- How is recycling coordinated for different classes of Golgi proteins?

Cisternal maturation involves the recycling of multiple classes of transmembrane and peripherally membrane-associated Golgi proteins, including glycosylation enzymes, sugar nucleotide transporters, SNAREs, vesicle tethers, guanine nucleotide exchange factors, and vesicle coat proteins. Candidates for coordinating this recycling are the Rab GTPases, which have been implicated in defining endomembrane compartments and membrane domains (Zerial \& McBride 2001). Multiple Rab proteins can function together in biochemical cascades (Markgraf et al 2007), and such a Rab cascade has been implicated in endosome maturation (Rink et al 2005). A similar mechanism might control Golgi maturation. For example, in yeast, the TRAPP I complex recruits the Rab protein Ypt1 to the early Golgi while the related TRAPP II complex recruits the Rab protein pair Ypt31/32 to the late Golgi (Morozova et al 2006). It seems plausible that TRAPP I is converted to TRAPP II during maturation, and that Ypt1 and Ypt31/32 help to define early and late Golgi compartments, respectively.

- Do Golgi compartments represent discrete kinetic stages of maturation?

Morphological studies have long supported the view that the Golgi comprises well-defined cis, medial, trans, and TGN compartments. These morphological distinctions are particularly clear in plant and algal cells (Donohoe et al 2007, Staehelin \& Kang 2008) but are also evident in other cell types. For example, the mammamlian Golgi displays a sharp transition between 
trans cisternae, which are devoid of clathrin, and TGN cisternae, which produce clathrin-coated vesicles (Ladinsky et al 1999, Ladinsky et al 2002). The existence of sharp transitions between well-defined Golgi compartments must be reconciled with the cisternal maturation model, which ostensibly replaces Golgi compartments with generic cisternae that lie along a continuum of maturation.

This paradox can be resolved by assuming that maturation occurs in discrete steps. In this view, the traditionally defined Golgi compartments represent different kinetic stages of maturation. Each stage would be defined by a unique relationship to older and younger cisternae. For example, a medial cisterna would export material only to cis cisternae while receiving material only from trans cisternae. The conversion from one stage to the next would be relatively fast, perhaps driven by a cooperative transition in a Rab cascade. Experimental tests of these ideas will require a better understanding of the events that drive cisternal maturation.

- Can different cisternae in the stack be functionally equivalent?

If Golgi maturation is a discrete process, there are probably no more than 3-4 kinetic stages. Yet many organisms have more than 3-4 cisternae per stack, suggesting that multiple cisternae can sometimes be functionally equivalent. For example, NRK cells seem to contain two trans cisternae (Ladinsky et al 2002). The implication is that retrograde COPI vesicles produced by a given cisterna can potentially fuse with any of several earlier cisternae.

- How can the $20^{\circ} \mathrm{C}$ block be reconciled with cisternal maturation?

This discussion has focused on issues that can be addressed within the framework of cisternal maturation. However, some observations are harder to explain. A notable example is the effect of incubating mammalian cells at $20^{\circ} \mathrm{C}$. Under these conditions, the early stages of the secretory pathway are operational but exit from the TGN is blocked (Griffiths et al 1989). The cisternal maturation model predicts that cisternae should pile up at $20^{\circ} \mathrm{C}$. Instead, the number of cisternae remains fixed, but secretory cargoes accumulate in enlarged trans and TGN cisternae (Ladinsky et al 2002). This finding does not fit with a simple conveyor belt model for cisternal maturation.

A solution to this problem is not obvious. One can explain the fixed number of cisternae at 20 ${ }^{\circ} \mathrm{C}$ by invoking a feedback mechanism that prevents new cis cisternae from being formed when TGN cisternae cannot be released. But then how do secretory cargoes reach the trans side of the stack at $20^{\circ} \mathrm{C}$ ? Perhaps the cargoes diffuse through intercisternal continuities and condense within trans and TGN cisternae, but such a mechanism is purely speculative. This uncertainty emphasizes that cisternal maturation is still a provisional framework for describing membrane traffic through the Golgi.

\section{Acknowledgments}

This work was supported by NIH grant GM-61156 to B.S.G., and by Grants-in-Aid for Scientific Research from the Ministry of Education, Culture, Sports, Science and Technology of Japan as well as a Bioarchitect Research Project of RIKEN ASI to A.K.

\section{References}

Altan-Bonnet N, Sougrat R, Liu W, Snapp EL, Ward T, Lippincott-Schwartz J. Golgi inheritance in mammalian cells is mediated through endoplasmic reticulum export activities. Mol. Biol. Cell 2006;17:990-1005. [PubMed: 16314396]

Ang AL, Taguchi T, Francis S, Fölsch H, Murrels JL, et al. Recycling endosomes can serve as intermediates during transport from the Golgi to the plasma membrane of MDCK cells. J. Cell Biol 2004;167:531-43. [PubMed: 15534004] 
Appenzeller-Herzog C, Hauri HP. The ER-Golgi intermediate compartment (ERGIC): in search of its identity and function. J. Cell Sci 2006;119:2173-83. [PubMed: 16723730]

Axelsson MA, Warren G. Rapid, endoplasmic reticulum-independent diffusion of the mitotic Golgi haze. Mol. Biol. Cell 2004;15:1843-52. [PubMed: 14767069]

Bard F, Malhotra V. The formation of TGN-to-plasma membrane transport carriers. Annu. Rev. Cell Dev. Biol 2006;22:439-55. [PubMed: 16824007]

Becker B, Melkonian M. The secretory pathway of protists: spatial and functional organization and evolution. Microbiol. Rev 1996;60:697-721. [PubMed: 8987360]

Ben-Tekaya H, Miura K, Pepperkok R, Hauri HP. Live imaging of bidirectional traffic from the ERGIC. J. Cell Sci 2005;118:357-67. [PubMed: 15632110]

Bentley M, Liang Y, Mullen K, Xu D, Sztul E, Hay JC. SNARE status regulates tether recruitment and function in homotypic COPII vesicle fusion. J. Biol. Chem 2006;281:38825-33. [PubMed: 17038314]

Bevis BJ, Hammond AT, Reinke CA, Glick BS. De novo formation of transitional ER sites and Golgi structures in Pichia pastoris. Nat. Cell Biol 2002;4:750-6. [PubMed: 12360285]

Boevink P, Oparka K, Santa Cruz S, Martin B, Betteridge A, Hawes C. Stacks on tracks: the plant Golgi apparatus traffics on an actin/ER network. Plant J 1998;15:441-7. [PubMed: 9750355]

Bonfanti L, Mironov AA Jr. Martínez-Menárguez J, Martella O, Fusella A, et al. Procollagen traverses the Golgi stack without leaving the lumen of cisternae: evidence for cisternal maturation. Cell 1998;95:993-1003. [PubMed: 9875853]

Bonifacino JS, Rojas R. Retrograde transport from endosomes to the trans-Golgi network. Nat. Rev. Mol. Cell Biol 2006;7:568-79. [PubMed: 16936697]

Boulaflous A, Faso C, Brandizzi F. Deciphering the Golgi apparatus: from imaging to genes. Traffic 2008;9:1613-7. [PubMed: 18503640]

Bracker CE, Morré DJ, Grove SN. Structure, differentiation and multiplication of Golgi apparatus in fungal hyphae. Protoplasma 1996;194:250-74.

Brangwynne CP, Koenderink GH, MacKintosh FC, Weitz DA. Cytoplasmic diffusion: molecular motors mix it up. J. Cell Biol 2008;183:583-7. [PubMed: 19001127]

Brigance WT, Barlowe C, Graham TR. Organization of the yeast Golgi complex into at least four functionally distinct compartments. Mol. Biol. Cell 2000;11:171-82. [PubMed: 10637300]

Brossard C, Bresson D, Polishchuk RS, Malhotra V. Dimeric PKD regulates membrane fission to form transport carriers at the TGN. J. Cell Biol 2007;179:1123-31. [PubMed: 18086912]

Brown WJ, Chambers K, Doody A. Phospholipase A2 (PLA2) enzymes in membrane trafficking: mediators of membrane shape and function. Traffic 2003;4:214-21. [PubMed: 12694560]

Cai H, Yu S, Menon S, Cai Y, Lazarova D, et al. TRAPP1 tethers COPII vesicles by binding the coat subunit Sec23. Nature 2007;445:941-4. [PubMed: 17287728]

Cluett EB, Brown WJ. Adhesion of Golgi cisternae by proteinaceous interactions: intercisternal bridges as putative adhesive structures. J. Cell Sci 1992;103:773-84. [PubMed: 1336017]

Cole NB, Sciaky N, Marotta A, Song J, Lippincott-Schwartz J. Golgi dispersal during microtubule disruption: regeneration of Golgi stacks at peripheral endoplasmic reticulum exit sites. Mol. Biol. Cell 1996a;7:631-50. [PubMed: 8730104]

Cole NB, Smith CL, Sciaky N, Terasaki M, Edidin M, Lippincott-Schwartz J. Diffusional mobility of Golgi proteins in membranes of living cells. Science 1996b;273:797-801. [PubMed: 8670420]

Colley KJ. Golgi localization of glycosyltransferases: more questions than answers. Glycobiology 1997;7:1-13. [PubMed: 9061359]

Copic A, Starr TL, Schekman R. Ent3p and Ent5p exhibit cargo-specific functions in trafficking proteins between the trans-Golgi network and the endosomes in yeast. Mol. Biol. Cell 2007;18:1803-15. [PubMed: 17344475]

Cosson P, Amherdt M, Rothman JE, Orci L. A resident Golgi protein is excluded from peri-Golgi vesicles in NRK cells. Proc. Natl. Acad. Sci. USA 2002;99:12831-4. [PubMed: 12223891]

Cosson P, Ravazzola M, Varlamov O, Söllner TH, Di Liberto M, et al. Dynamic transport of SNARE proteins in the Golgi apparatus. Proc. Natl. Acad. Sci. USA 2005;102:14647-52. [PubMed: 16199514] 
Dacks JB, Davis LA, Sjögren AM, Andersson JO, Roger AJ, Doolittle WF. Evidence for Golgi bodies in proposed 'Golgi-lacking' lineages. Proc. Biol. Sci 2003;270(Suppl. 2):S168-S71. [PubMed: 14667372]

Dahan S, Ahluwalia JP, Wong L, Posner BI, Bergeron JJM. Concentration of intracellular hepatic apolipoprotein E in Golgi apparatus saccular distensions and endosomes. J. Cell Biol 1994;127:1859_ 69. [PubMed: 7806565]

De Matteis MA, Luini A. Exiting the Golgi complex. Nat. Rev. Mol. Cell Biol 2008;9:273-84. [PubMed: 18354421]

Dikeakos JD, Reudelhuber TL. Sending proteins to dense core secretory granules: still a lot to sort out. J. Cell Biol 2007;177:191-6. [PubMed: 17438078]

Dinter A, Berger EG. Golgi-disturbing agents. Histochem. Cell Biol 1998;109:571-90. [PubMed: 9681636]

Domozych DS. The Golgi apparatus and membrane trafficking in green algae. Int. Rev. Cytol 1991;131:213-53. [PubMed: 1761384]

Donohoe BS, Kang BH, Staehelin LA. Identification and characterization of COPIa- and COPIb-type vesicle classes associated with plant and algal Golgi. Proc. Natl. Acad. Sci. USA 2007;104:163-8. [PubMed: 17185411]

Duden, R.; Schekman, R. Insights into Golgi function through mutants in yeast and animal cells. In: Berger, EG.; Roth, J., editors. The Golgi Apparatus. Birkhäuser Verlag; Basel: 1997. p. 219-46.

Dunphy WG, Rothman JE. Compartmental organization of the Golgi stack. Cell 1985;42:13-21. [PubMed: 3926324]

Efimov A, Kharitonov A, Efimova N, Loncarek J, Miller PM, et al. Asymmetric CLASP-dependent nucleation of noncentrosomal microtubules at the trans-Golgi network. Dev. Cell 2007;12:917-30. [PubMed: 17543864]

Farquhar MG. Progress in unraveling pathways of Golgi traffic. Annu. Rev. Cell Biol 1985;1:447-88. [PubMed: 3916320]

Foresti O, Denecke J. Intermediate organelles of the plant secretory pathway: identity and function. Traffic 2008;9:1599-612. [PubMed: 18627574]

Franzusoff A, Redding K, Crosby J, Fuller RS, Schekman R. Localization of components involved in protein transport and processing through the yeast Golgi apparatus. J. Cell Biol 1991;112:27-37. [PubMed: 1986005]

Gilchrist A, Au CE, Hiding J, Bell AW, Fernandez-Rodriguez J, et al. Quantitative proteomics analysis of the secretory pathway. Cell 2006;127:1265-81. [PubMed: 17174899]

Glick BS, Elston T, Oster G. A cisternal maturation mechanism can explain the asymmetry of the Golgi stack. FEBS Lett 1997;414:177-81. [PubMed: 9315681]

Glick BS, Malhotra V. The curious status of the Golgi apparatus. Cell 1998;95:883-9. [PubMed: 9875843]

Gong H, Sengupta D, Linstedt AD, Schwartz R. Simulated de novo assembly of Golgi compartments by selective cargo capture during vesicle budding and targeted vesicle fusion. Biophys. J 2008;95:167488. [PubMed: 18469086]

Grabenbauer M, Geerts WJ, Fernandez-Rodriguez J, Hoenger A, Koster AJ, Nilsson T. Correlative microscopy and electron tomography of GFP through photooxidation. Nat. Methods 2005;2:857-62. [PubMed: 16278657]

Griffiths G, Fuller SD, Back R, Hollinshead M, Pfeiffer S, Simons K. The dynamic nature of the Golgi complex. J. Cell Biol 1989;108:277-97. [PubMed: 2537312]

Hammond AT, Glick BS. Dynamics of transitional endoplasmic reticulum sites in vertebrate cells. Mol. Biol. Cell 2000;11:3013-30. [PubMed: 10982397]

Hanada K, Kumagai K, Tomishige N, Kawano M. CERT and intracellular trafficking of ceramide. Biochim. Biophys. Acta 2007;1771:644-53. [PubMed: 17314061]

Hanton SL, Matheson LA, Chatre L, Brandizzi F. Dynamic organization of COPII coat proteins at endoplasmic reticulum export sites in plant cells. Plant J. 2008 Epub ahead of print.

Harris SL, Waters MG. Localization of a yeast early Golgi mannosyltransferase, Och1p, involves retrograde transport. J. Cell Biol 1996;132:985-98. [PubMed: 8601597] 
Harsay E, Schekman R. A subset of yeast vacuolar protein sorting mutants is blocked in one branch of the exocytic pathway. J. Cell Biol 2002;156:271-85. [PubMed: 11807092]

Hawes C, Osterrieder A, Hummel E, Sparkes I. The plant ER-Golgi interface. Traffic 2008;9:1571-80. [PubMed: 18513377]

Hayes GL, Brown FC, Haas AK, Nottingham RM, Barr FA, Pfeffer SR. Multiple Rab GTPase binding sites in GCC185 suggest a model for vesicle tethering at the trans-Golgi. Mol. Biol. Cell 2009;20:209-17. [PubMed: 18946081]

He CY, Ho HH, Malsam J, Chalouni C, West CM, et al. Golgi duplication in Trypanosoma brucei. J. Cell Biol 2004;165:313-21. [PubMed: 15138289]

Hinners I, Tooze SA. Changing directions: clathrin-mediated transport between the Golgi and endosomes. J. Cell Sci 2003;116:763-71. [PubMed: 12571274]

Ho HH, He CY, de Graffenried CL, Murrells LJ, Warren G. Ordered assembly of the duplicating Golgi in Trypanosoma brucei. Proc. Natl. Acad. Sci. USA 2006;103:7676-81. [PubMed: 16672362]

Hoe MH, Slusarewicz P, Misteli T, Watson R, Warren G. Evidence for recycling of the resident medial/ trans Golgi enzyme, N-acetylglucosaminyltransferase I, in ldlD cells. J. Biol. Chem 1995;270:25057-63. [PubMed: 7559636]

Hughes H, Stephens DJ. Assembly, organization, and function of the COPII coat. Histochem. Cell Biol 2008;129:129-51. [PubMed: 18060556]

Jiang S, Rhee SW, Gleeson PA, Storrie B. Capacity of the Golgi apparatus for cargo transport prior to complete assembly. Mol. Biol. Cell 2006;17:4105-17. [PubMed: 16837554]

Johannes L, Popoff V. Tracing the retrograde route in protein trafficking. Cell 2008;135:1175-87. [PubMed: 19109890]

Kang BH, Staehelin LA. ER-to-Golgi transport by COPII vesicles in Arabidopsis involves a ribosomeexcluding scaffold that is transferred with the vesicles to the Golgi matrix. Protoplasma 2008;234:5164. [PubMed: 18810574]

Kreis, TE.; Goodson, HV.; Perez, F.; Rönnholm, R. Golgi apparatus-cytoskeleton interactions. In: Berger, EG.; Roth, J., editors. The Golgi Apparatus. Birkhäuser Verlag; Basel: 1997. p. 179-93.

Kweon HS, Beznoussenko GV, Micaroni M, R.S. P, Trucco A, et al. Golgi enzymes are enriched in perforated zones of Golgi cisternae but are depleted in COPI vesicles. Mol. Biol. Cell 2004;15:471024. [PubMed: 15282336]

Ladinsky MS, Mastronarde DN, McIntosh JR, Howell KE, Staehelin LA. Golgi structure in three dimensions: functional insights from the normal rat kidney cell. J. Cell Biol 1999;144:1135-49. [PubMed: 10087259]

Ladinsky MS, Wu CC, McIntosh S, McIntosh JR, Howell KE. Structure of the Golgi and distribution of reporter molecules at $20^{\circ} \mathrm{C}$ reveals the complexity of the exit compartments. Mol. Biol. Cell 2002;13:2810-25. [PubMed: 12181348]

Lewis MJ, Nichols BJ, Prescianotto-Baschong C, Riezman H, Pelham HRB. Specific retrieval of the exocytic SNARE Snc1p from early yeast endosomes. Mol. Biol. Cell 2000;11:23-38. [PubMed: 10637288]

Li X, Kaloyanova D, van Eijk M, Eerland R, van der Goot G, et al. Involvement of a Golgi-resident GPIanchored protein in maintenance of the Golgi structure. Mol. Biol. Cell 2007;18:1261-71. [PubMed: 17251550]

Lippincott-Schwartz J, Yuan L, Tipper C, Amherdt M, Orci L, Klausner RD. Brefeldin A's effects on endosomes, lysosomes, and the TGN suggest a general mechanism for regulating organelle structure and membrane traffic. Cell 1991;67:601-16. [PubMed: 1682055]

Liu K, Surendhran K, Nothwehr SF, Graham TR. P4-ATPase requirement for AP-1/clathrin function in protein transport from the trans-Golgi network and early endosomes. Mol. Biol. Cell 2008;19:352635. [PubMed: 18508916]

Losev E, Reinke CA, Jellen J, Strongin DE, Bevis BJ, Glick BS. Golgi maturation visualized in living yeast. Nature 2006;22:1002-6. [PubMed: 16699524]

Love HD, Lin C-C, Short CS, Ostermann J. Isolation of functional Golgi-derived vesicles with a possible role in retrograde transport. J. Cell Biol 1998;140:541-51. [PubMed: 9456315]

Lowe M, Barr FA. Inheritance and biogenesis of organelles in the secretory pathway. Nat. Rev. Mol. Cell Biol 2007;8:429-39. [PubMed: 17505521] 
Luby-Phelps K. Cytoarchitecture and physical properties of cytoplasm: volume, viscosity, diffusion, intracellular surface area. Int. Rev. Cytol 2000;192:189-221. [PubMed: 10553280]

Luini A, Mironov AA, Polishchuk EV, Polishchuk RS. Morphogenesis of post-Golgi transport carriers. Histochem. Cell Biol 2008;129:153-61. [PubMed: 18214517]

Maeda Y, Ide T, Koike M, Uchiyama Y, Kinoshita T. GPHR is a novel anion channel critical for acidification and functions of the Golgi apparatus. Nat. Cell Biol 2008;10:1135-45. [PubMed: 18794847]

Malsam J, Satoh A, Pelletier L, Warren G. Golgin tethers define subpopulations of COPI vesicles. Science 2005;307:1095-8. [PubMed: 15718469]

Manderson AP, Kay JG, Hammond LA, Brown DL, Stow JL. Subcompartments of the macrophage recycling endosome direct the differential secretion of IL-6 and TNF $\alpha$. J. Cell Biol 2007;178:57-69. [PubMed: 17606866]

Mardones GA, Snyder CM, Howell KE. cis-Golgi matrix proteins move directly to endoplasmic reticulum exit sites by association with tubules. Mol. Biol. Cell 2006;17:525-38. [PubMed: 16251359]

Markgraf DF, Peplowska K, Ungermann C. Rab cascades and tethering factors in the endomembrane system. FEBS Lett 2007;581:2125-30. [PubMed: 17316615]

Marra P, Salvatore L, Mironov A Jr. Di CAmpli A, Di Tullio G, et al. The biogenesis of the Golgi ribbon: the roles of membrane input from the ER and of GM130. Mol. Biol. Cell 2007;18:1595-608. [PubMed: 17314401]

Marsh BJ, Volkmann N, McIntosh JR, Howell KE. Direct continuities between cisternae at different levels of the Golgi complex in glucose-stimulated mouse islet beta cells. Proc. Natl. Acad. Sci. USA 2004;101:5565-70. [PubMed: 15064406]

Martínez-Alonso E, Ballesta J, Martínez-Menárguez JA. Low-temperature-induced Golgi tubules are transient membranes enriched in molecules regulating intra-Golgi transport. Traffic 2007;8:359-68. [PubMed: 17274796]

Martínez-Menárguez JA, Prekeris R, Oorschot VMJ, Scheller R, Slot JW, et al. Peri-Golgi vesicles contain retrograde but not anterograde proteins consistent with the cisternal progression model of intra-Golgi transport. J. Cell Biol 2001;155:1213-24. [PubMed: 11748250]

Matsuura-Tokita K, Takeuchi M, Ichihara A, Mikuriya K, Nakano A. Live imaging of yeast Golgi cisternal maturation. Nature 2006;22:1007-10. [PubMed: 16699523]

Maxfield FR, McGraw TE. Endocytic recycling. Nat. Rev. Mol. Cell Biol 2004;5:121-32. [PubMed: 15040445]

Mellman I, Simons K. The Golgi complex: in vitro veritas? Cell 1992;68:829-40. [PubMed: 1547485]

Miles S, McManus H, Forsten KE, Storrie B. Evidence that the entire Golgi apparatus cycles in interphase HeLa cells: sensitivity of Golgi matrix proteins to an ER exit block. J. Cell Biol 2001;155:543-56. [PubMed: 11696556]

Mironov AA, Beznoussenko GV, Nicoziani P, Martella O, Trucco A, et al. Small cargo proteins and large aggregates can traverse the Golgi by a common mechanism without leaving the lumen of cisternae. J. Cell Biol 2001;155:1225-38. [PubMed: 11756473]

Mogelsvang S, Gomez-Ospina N, Soderholm J, Glick BS, Staehelin LA. Tomographic evidence for continuous turnover of Golgi cisternae in Pichia pastoris. Mol. Biol. Cell 2003;14:2277-91. [PubMed: 12808029]

Mogelsvang S, Marsh BJ, Ladinsky MS, Howell KE. Predicting function from structure: 3D structure studies of the mammalian Golgi complex. Traffic 2004;5:338-45. [PubMed: 15086783]

Mollenhauer HH, Morré DJ. Perspectives on Golgi apparatus form and function. J. Electron Microsc. Tech 1991;17:2-14. [PubMed: 1993935]

Morozova N, Liang Y, Tokarev AA, Chen SH, Cox R, et al. TRAPPII subunits are required for the specificity switch of a Ypt-Rab GEF. Nat. Cell Biol 2006;8:1263-9. [PubMed: 17041589]

Nebenführ A, Gallagher LA, Dunahay TG, Frohlick JA, Mazurkiewicz AM, et al. Stop- and-go movements of plant Golgi stacks are mediated by the acto-myosin system. Plant Physiol 1999;121:1127-42. [PubMed: 10594100]

Opat AS, van Vliet C, Gleeson PA. Trafficking and localisation of resident Golgi glycosylation enzymes. Biochimie 2001;83:763-73. [PubMed: 11530209] 
Orci L, Amherdt M, Ravazzola M, Perrelet A, Rothman JE. Exclusion of Golgi residents from transport vesicles budding from Golgi cisternae in intact cells. J. Cell Biol 2000a;150:1263-70. [PubMed: 10995433]

Orci L, Glick BS, Rothman JE. A new type of coated vesicular carrier that appears not to contain clathrin: its possible role in protein transport within the Golgi stack. Cell 1986;46:171-84. [PubMed: 2872969]

Orci L, Ravazzola M, Volchuk A, Engel T, Gmachl M, et al. Anterograde flow of cargo across the Golgi stack potentially mediated via bidirectional "percolating” COPI vesicles. Proc. Natl. Acad. Sci. USA 2000b;97:10400-5. [PubMed: 10962035]

Orci L, Stamnes M, Ravazzola M, Amherdt M, Perrelet A, et al. Bidirectional transport by distinct populations of COPI-coated vesicles. Cell 1997;90:335-49. [PubMed: 9244307]

Patterson GH, Hirschberg K, Polishchuk RS, Gerlich D, Phair RD, Lippincott-Schwartz J. Transport through the Golgi apparatus by rapid partitioning within a two-phase membrane system. Cell 2008;133:1055-67. [PubMed: 18555781]

Pecot MY, Malhotra V. The Golgi apparatus maintains its organization independent of the endoplasmic reticulum. Mol. Biol. Cell 2006;17:5372-80. [PubMed: 17050735]

Pelham HR, Rothman JE. The debate about transport in the Golgi--two sides of the same coin? Cell 2000;102:713-9. [PubMed: 11030615]

Pelham HRB. Getting through the Golgi complex. Trends Cell Biol 1998;8:45-9. [PubMed: 9695808]

Peretti D, Dahan N, Shimoni E, Hirschberg K, Lev S. Coordinated lipid transfer between the endoplasmic reticulum and the Golgi complex requires the VAP proteins and is essential for Golgi-mediated transport. Mol. Biol. Cell 2008;19:3871-84. [PubMed: 18614794]

Presley JF, Cole NB, Schroer TA, Hirschberg K, Zaal KJM, Lippincott-Schwartz J. ER-to-Golgi transport visualized in living cells. Nature 1997;389:81-5. [PubMed: 9288971]

Preuss D, Mulholland J, Franzusoff A, Segev N, Botstein D. Characterization of the Saccharomyces Golgi complex through the cell cycle by immunoelectron microscopy. Mol. Biol. Cell 1992;3:789-803. [PubMed: 1381247]

Puri S, Linstedt AD. Capacity of the Golgi apparatus for biogenesis from the endoplasmic reticulum. Mol. Biol. Cell 2003;14:5011-8. [PubMed: 14565973]

Puri S, Telfer H, Velliste M, Murphy RF, Linstedt AD. Dispersal of Golgi matrix proteins during mitotic Golgi disassembly. J. Cell Sci 2004;117:451-6. [PubMed: 14679306]

Puthenveedu MA, Bachert C, Puri S, Lanni F, Linstedt AD. GM130 and GRASP65-dependent lateral cisternal fusion allows uniform Golgi-enzyme distribution. Nat. Cell Biol 2006;8:238-48. [PubMed: 16489344]

Rabouille C, Hui N, Hunte F, Kieckbusch R, Berger EG, et al. Mapping the distribution of Golgi enzymes involved in the construction of complex oligosaccharides. J. Cell Sci 1995;108:1617-27. [PubMed: 7615680]

Rabouille C, Klumperman J. Opinion: The maturing role of COPI vesicles in intra-Golgi transport. Nat. Rev. Mol. Cell Biol 2005;6:812-7. [PubMed: 16167055]

Rambourg A, Clermont Y. Three-dimensional electron microscopy: structure of the Golgi apparatus. Eur. J. Cell Biol 1990;51:189-200. [PubMed: 2190832]

Reinke CA, Kozik P, Glick BS. Golgi inheritance in Saccharomyces cerevisiae depends on ER inheritance. Proc. Natl. Acad. Sci. USA 2004;101:18018-23. [PubMed: 15596717]

Rink J, Ghigo E, Kalaidzidis Y, Zerial M. Rab conversion as a mechanism of progression from early to late endosomes. Cell 2005;122:735-49. [PubMed: 16143105]

Robinson DG, Jiang L, Schumacher K. The endosomal system of plants: charting new and familiar territories. Plant Physiol 2008;147:1482-92. [PubMed: 18678740]

Rodriguez-Boulan E, Müsch A. Protein sorting in the Golgi complex: shifting paradigms. Biochim. Biophys. Acta 2005;1744:455-64. [PubMed: 15927284]

Rogalski AA, Bergmann JE, Singer SJ. Effect of microtubule assembly status on the intracellular processing and surface expression of an integral protein of the plasma membrane. J. Cell Biol 1984;99:1101-9. [PubMed: 6088553]

Rossanese OW, Glick BS. Deconstructing Golgi inheritance. Traffic 2001;2:589-96. [PubMed: 11555412] 
Rossanese OW, Soderholm J, Bevis BJ, Sears IB, O’Connor J, et al. Golgi structure correlates with transitional endoplasmic reticulum organization in Pichia pastoris and Saccharomyces cerevisiae. J. Cell Biol 1999;145:69-81. [PubMed: 10189369]

Rothman JE, Urbani LJ, Brands R. Transport of proteins between cytoplasmic membranes of fused cells: correspondence to processes reconstituted in a cell-free system. J. Cell Biol 1984;99:248-59. [PubMed: 6429157]

Rothman JE, Warren G. Implications of the SNARE hypothesis for intracellular membrane topology and dynamics. Curr. Biol 1994;4:220-33. [PubMed: 7922327]

Rothman JE, Wieland FT. Protein sorting by transport vesicles. Science 1996;272:227-34. [PubMed: 8602507]

Sato K, Nakano A. Mechanisms of COPII vesicle formation and protein sorting. FEBS Lett 2007;581:2076-82. [PubMed: 17316621]

Schmitz KR, Liu J, Li S, Setty TG, Wood CS, et al. Golgi localization of glycosyltransferases requires a Vps74p oligomer. Dev. Cell 2008;14:523-34. [PubMed: 18410729]

Sciaky N, Presley J, Smith C, Zaal KJM, Cole N, et al. Golgi tubule traffic and the effects of brefeldin A visualized in living cells. J. Cell Biol 1997;139:1137-55. [PubMed: 9382862]

Seemann J, Jokitalo E, Pypaert M, Warren G. Matrix proteins can generate the higher order architecture of the Golgi apparatus. Nature 2000;407:1022-6. [PubMed: 11069184]

Shen X, Xu KF, Fan Q, Pacheco-Rodriguez G, Moss J, Vaughan M. Association of brefeldin A-inhibited guanine nucleotide-exchange protein 2 (BIG2) with recycling endosomes during transferrin uptake. Proc. Natl. Acad. Sci. USA 2006;103:2635-40. [PubMed: 16477018]

Shin HW, Morinaga N, Noda M, Nakayama K. BIG2, a guanine nucleotide exchange factor for ADPribosylation factors: its localization to recycling endosomes and implication in the endosome integrity. Mol. Biol. Cell 2004;15:5283-94. [PubMed: 15385626]

Short B, Haas A, Barr FA. Golgins and GTPases, giving identity and structure to the Golgi apparatus. Biochim. Biophys. Acta 2005;1744:383-95. [PubMed: 15979508]

Shorter J, Warren G. Golgi architecture and inheritance. Annu. Rev. Cell Dev. Biol 2002;18:379-420. [PubMed: 12142281]

Sinka R, Gillingham AK, Kondylis V, Munro S. Golgi coiled-coil proteins contain multiple binding sites for Rab family G proteins. J. Cell Biol 2008;183:607-15. [PubMed: 19001129]

Smith RD, Lupashin VV. Role of the conserved oligomeric Golgi (COG) complex in protein glycosylation. Carbohydr. Res 2008;343:2024-31. [PubMed: 18353293]

Staehelin LA, Kang BH. Nanoscale architecture of endoplasmic reticulum export sites and of Golgi membranes as determined by electron tomography. Plant Physiol 2008;147:1454-68. [PubMed: 18678738]

Staehelin LA, Moore I. The plant Golgi apparatus: structure, functional organization and trafficking mechanisms. Annu. Rev. Plant Physiol. Plant Mol. Biol 1995;46:261-88.

Trautwein M, Schindler C, Gauss R, Dengjel J, Hartmann E, Spang A. Arf1p, Chs5p and the ChAPs are requires for export of specialized cargo from the Golgi. EMBO J 2006;25:943-54. [PubMed: 16498409]

Trucco A, Polishchuk RS, Martella O, Pentima AD, Fusella A, et al. Secretory traffic triggers the formation of tubular continuities across Golgi sub-compartments. Nat. Cell Biol 2004;6:1071-81. [PubMed: 15502824]

Tu L, Tai WC, Chen L, Banfield DK. Signal-mediated dynamic retention of glycosyltransferases in the Golgi. Science 2008;321:404-7. [PubMed: 18635803]

Uemura T, Ueda T, Ohniwa RL, Nakano A, Takeyasu K, Sato MH. Systematic analysis of SNARE molecules in Arabidopsis: dissection of the post-Golgi network in plant cells. Cell Struct. Funct 2004;29:49-65. [PubMed: 15342965]

Ungar D, Oka T, Krieger M, Hughson FM. Retrograde transport on the COG railway. Trends Cell Biol 2006;16:113-20. [PubMed: 16406524]

Volchuk A, Amherdt M, Ravazzola M, Brugger B, Rivera VM, et al. Megavesicles implicated in the rapid transport of intracisternal aggregates across the Golgi stack. Cell 2000;102:335-48. [PubMed: 10975524] 
Wang CW, Hamamoto S, Orci L, Schekman R. Exomer: a coat complex for transport of select membrane proteins from the trans-Golgi network to the plasma membrane in yeast. J. Cell Biol 2006;174:97383. [PubMed: 17000877]

Wang Y, Wei JH, Bisel B, Tang D, Seemann J. Golgi cisternal unstacking stimulates COPI vesicle budding and protein transport. PLoS ONE 2008;3:e1647. [PubMed: 18297130]

Ward TH, Polishchuk RS, Caplan S, Hirschberg K, Lippincott-Schwartz J. Maintenance of Golgi structure and function depends on the integrity of ER export. J. Cell Biol 2001;155:557-70. [PubMed: 11706049]

Weidman P, Roth R, Heuser J. Golgi membrane dynamics imaged by freeze-etch electron microscopy: views of different membrane coatings involved in tubulation versus vesiculation. Cell 1993;75:12333. [PubMed: 8402891]

Weidman PJ. Anterograde transport through the Golgi complex: do Golgi tubules hold the key? Trends Cell Biol 1995;5:302-5. [PubMed: 14732088]

Weiss M, Nilsson T. Protein sorting in the Golgi apparatus: a consequence of maturation and triggered sorting. FEBS Lett 2000;486:2-9. [PubMed: 11108832]

Wood SA, Park JE, Brown WJ. Brefeldin A causes a microtubule-meidated fusion of the trans-Golgi network and early endosomes. Cell 1991;67:591-600. [PubMed: 1657400]

Wooding S, Pelham HRB. The dynamics of Golgi protein traffic visualized in living yeast cells. Mol. Biol. Cell 1998;9:2667-80. [PubMed: 9725919]

Yang JS, Gad H, Lee SY, Mironov A, Zhang L, et al. A role for phosphatidic acid in COPI vesicle fission yields insights into Golgi maintenance. Nat. Cell Biol 2008;10:1146-53. [PubMed: 18776900]

Yang YD, Elamawi R, Bubeck J, Pepperkok R, Ritzenthaler C, Robinson DG. Dynamics of COPII vesicles and the Golgi apparatus in cultured Nicotiana tabacum BY-2 cells provides evidence for transient association of Golgi stacks with endoplasmic reticulum exit sites. Plant Cell 2005;17:1513-31. [PubMed: 15805489]

Zaal KJ, Smith CL, Polishchuk RS, Altan N, Cole NB, et al. Golgi membranes are absorbed into and reemerge from the ER during mitosis. Cell 1999;99:589-601. [PubMed: 10612395]

Zerial M, McBride H. Rab proteins as membrane organizers. Nat. Rev. Mol. Cell Biol 2001;2:107-17. [PubMed: 11252952] 


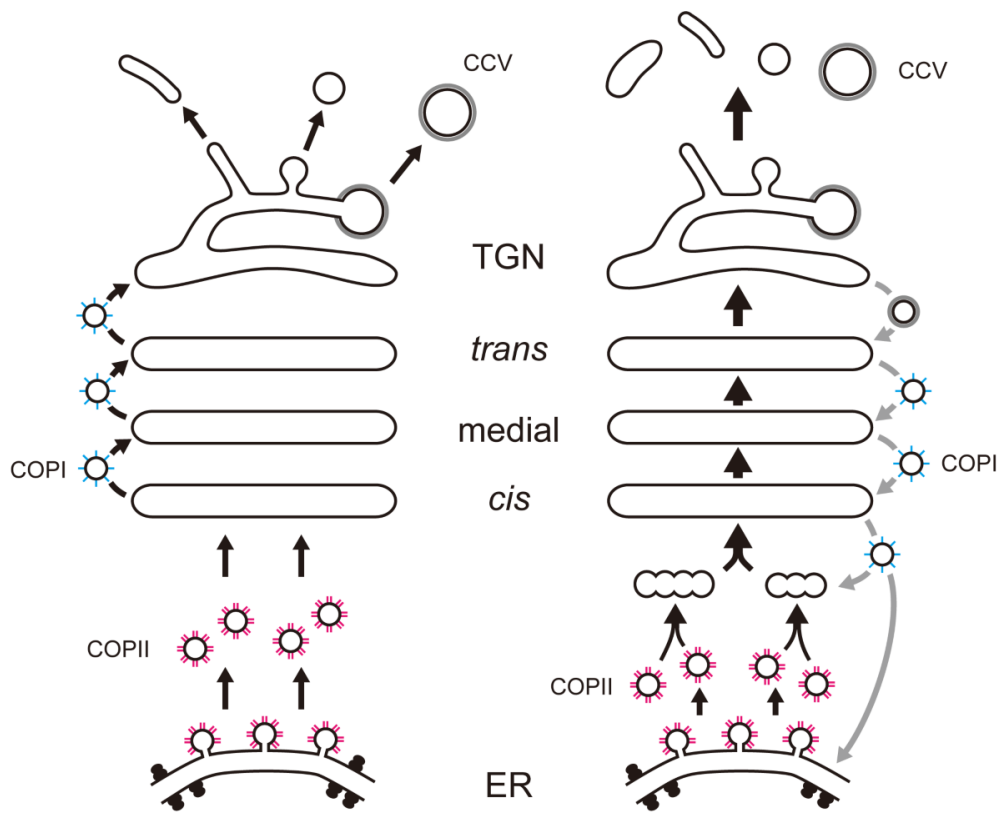

(a)

(b)

Figure 1. Two models for membrane traffic through the Golgi

(a) Stable compartments model. According to this view, cis-, medial-, and trans-Golgi cisternae as well as the trans-Golgi network (TGN) are long-lived entities that retain distinct sets of resident Golgi proteins. Secretory cargoes travel from one Golgi compartment to the next in anterograde COPI vesicles, and then exit the TGN in clathrin-coated vesicles (CCV) or secretory carriers. ER-to-Golgi transport is regarded as a donor-acceptor pathway connected by COPII vesicles. (b) Cisternal maturation model. According to this view, Golgi cisternae are transient structures that form de novo by the coalescence of COPII vesicles. A new cisterna matures from cis to trans, and then breaks down into transport carriers at the TGN stage. Cargoes are transported through the Golgi by cisternal progression. Maturation is driven by the retrograde transport of resident Golgi proteins. This retrograde transport involves COPI vesicles within the Golgi, and may also involve clathrin-mediated recycling from a maturing TGN compartment. 


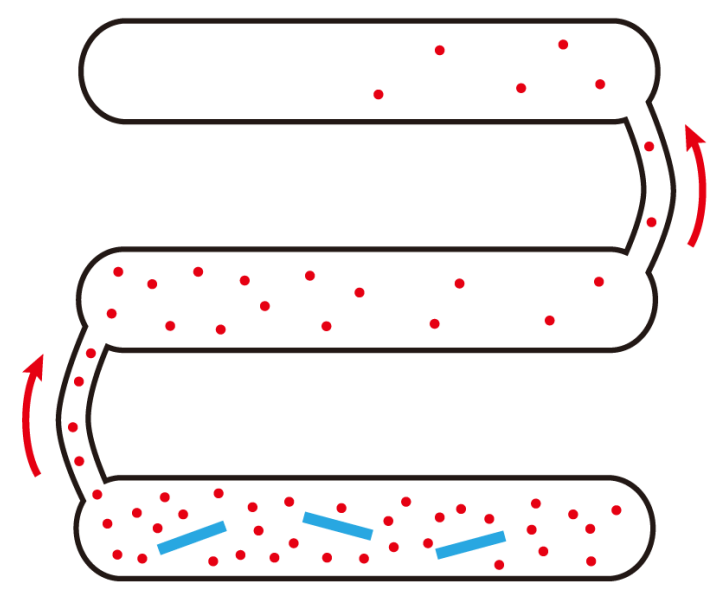

\section{anterograde traffic of small cargo}

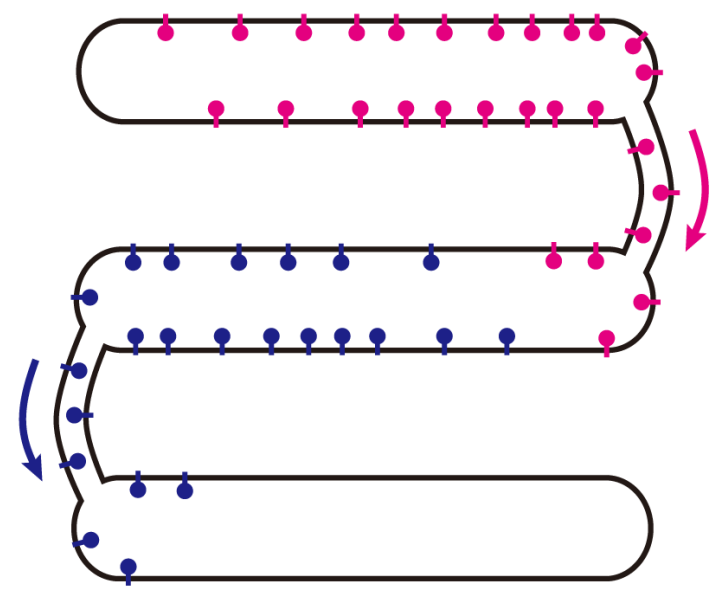

\section{retrograde traffic of membrane residents}

Figure 2. Possible roles of tubules that connect heterologous Golgi cisternae

(a) Tubules might transport small soluble secretory cargoes (red) in an anterograde fashion. Large secretory cargoes (blue) cannot follow this path and thus move forward exclusively by cisternal progression. (b) Tubules might facilitate cisternal maturation by allowing the retrograde diffusion of resident Golgi proteins (pink and purple). These two possibilities are not mutually exclusive. 


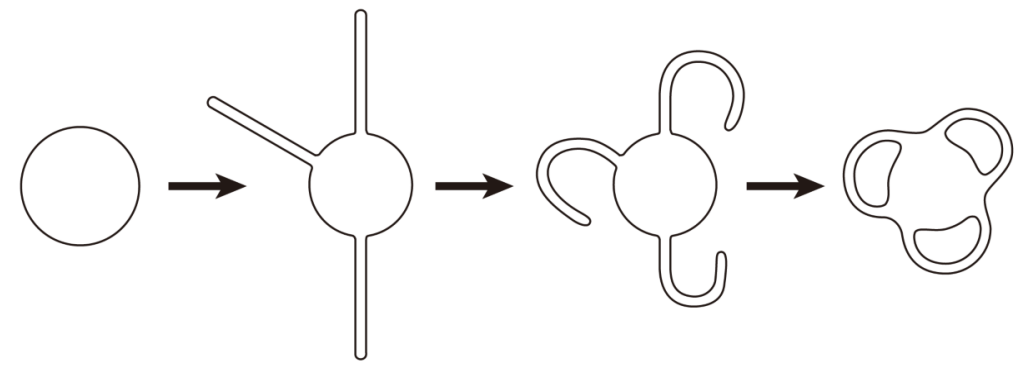

Figure 3. Tubules may give rise to cisternal fenestrations

We speculate that fenestrations are formed at the periphery of a cisterna when tubules fuse homotypically with the originating cisterna. 


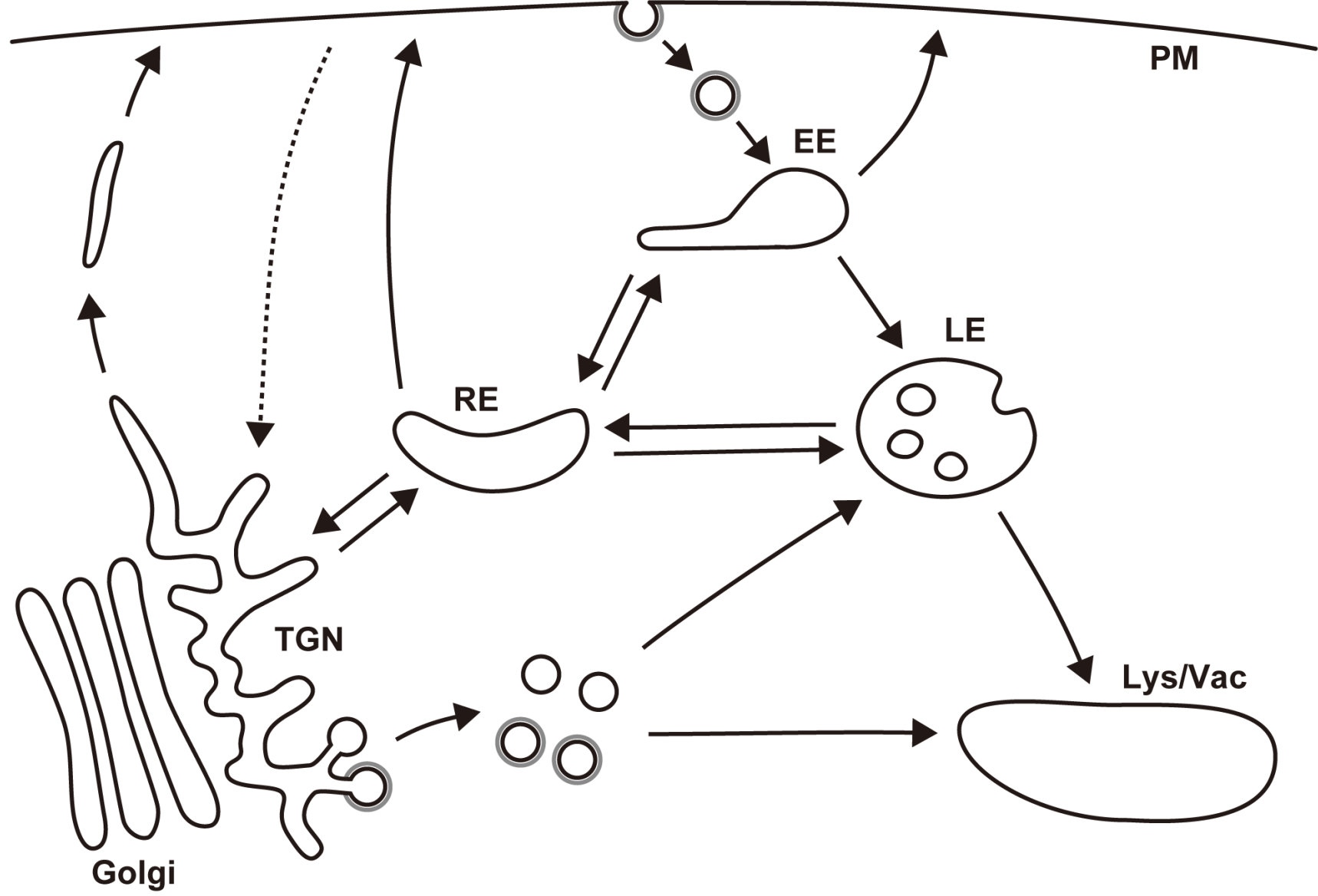

Figure 4. A model for post-Golgi membrane traffic

This model incorporates existing evidence to depict trafficking steps between exocytic, endocytic, and lysosomal/vacuolar compartments. Transport from the TGN to late endosomes (LE) and the lysosome/vacuole (Lys/Vac) is mediated by vesicles, some of which are coated with clathrin (gray). Transport from the TGN to the plasma membrane (PM) can be either direct, or indirect via fusion of TGN-derived carriers with recycling endosomes (RE). Recycling endosomes also receive material that was previously endocytosed to early endosomes (EE). The dashed line from the PM to the TGN is based on recent tentative findings in plant cells. 


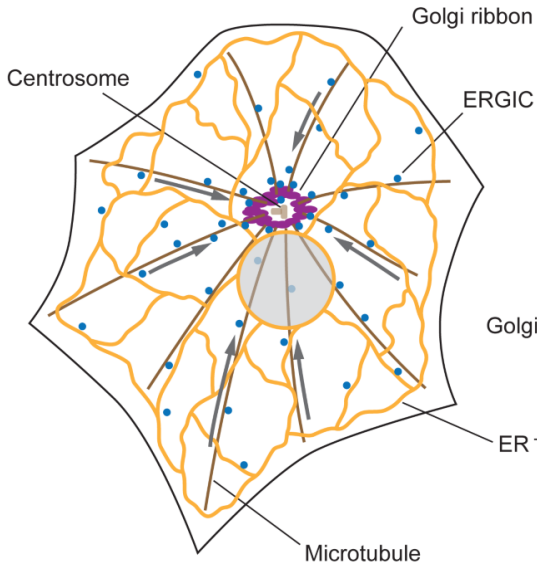

Mammalian Cell

(a)

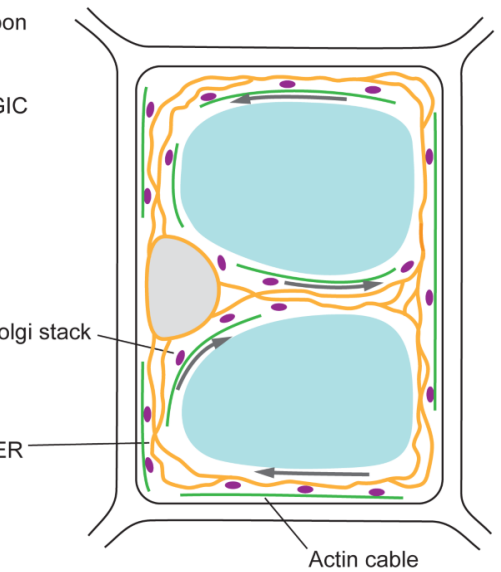

Plant Cell

(b)

Figure 5. Comparison of secretory pathway organization in mammalian and plant cells (a) In mammalian cells, Golgi stacks form an interconnected Golgi ribbon in the perinuclear centrosomal region. Pre-Golgi ERGIC (ER-Golgi intermediate compartment) elements form in the cell periphery and then undergo dynein-dependent transport along microtubules (arrows) to the Golgi ribbon. (b) In plant cells, the ER is often connected to the actin cable network, and individual Golgi stacks move along actin cables (arrows) by the action of myosin motors. 